\title{
Preparation and Evaluation of Electrical Properties of Plastic Composites Developed from Recycled Polystyrene and Local Clay
}

\author{
S. A. Abdulkareem, A. G. Adeniyi* \\ Department of Chemical Engineering, University of Ilorin, Ilorin, Nigeria.
}

\begin{abstract}
In this study, the development of polymer composites was achieved from local clay material and waste polystyrene by cold pressing method, the preparation, electrical, and physical behaviours of clay-polystyrene composites are described. Polystyrene based resin (PBR) was produced from waste polystyrene by solvolysis in petroleum solvent and mixed with the $100 \mu \mathrm{m}$ clay particles at $10 \%, 20 \%, 30 \%$, and $40 \%$ clay contents. Composite panels were prepared and tested for Physical and electrical properties. Metallurgical microscope was used for the microstructural studies. It was found that with the increase in clay content in PBR from 0 to $40 \%$, there was a rise in density of the composite by about $11 \%$ with a simultaneous decrease in the void fraction or porosity from $5.3 \%$ to $1.5 \%$. It was also observed that the polymer composite with the filler loading of $40 \mathrm{wt} \%$ has the highest conductivity value of $1.88 \mathrm{E}-07 \mathrm{~S} / \mathrm{cm}$. The comparison of micrographs at $40 \mathrm{x}$ and $100 \mathrm{x}$ indicated a good dispersion and distribution of clay particles in the polystyrene matrix. The polymer composites produced can be adapted for applications where electrostatic dissipative materials are required.
\end{abstract}

KEYWORDS: Electrical property, iron fillings, plastic composite, recycled polystyrene, clay particles.

[Received November 29 2017; Revised March 20 2018; Accepted March 24 2018]

Print ISSN: 0189-9546 | Online ISSN: 2437-2110

\section{INTRODUCTION}

Conductive plastic composites are practicable by impregnation of fillers into the prepared plastic matrix. High filler loadings of the prepared plastic matrix are usually needed to generate network of conductive channels and achieve an enhanced electrical conductivity in the plastic composite material produced (Alam, 2008). These plastic materials can be filled with several inorganic and/or natural compounds in order to get the wide array of property enhancements such as increased stiffness and strength, greater dimensional stability etc. Many factors such as electrical conductivity of fillers, diameter and structure of fillers, state of dispersion, process type, and most importantly the concentration of fillers affect the performance of conductive composites (Zeng et al., 2005).

A great deal of research results have appeared recently in the literature to indicate the alternative approaches to the production of electrically semi-conducting plastic composite materials that could effectively replace metallic components with mineral fillers to produce moderately conducting plastic composites (Wang, 2006; Tanniru etal., 2006). The addition of mineral fillers like clay, aluminium nitride (AlN), boron nitride $(\mathrm{BN})$, silicon carbide $(\mathrm{SiC})$ and beryllium oxide $(\mathrm{BeO})$ to thermoplastic and thermosetting plastics has been demonstrated to be an effective way of improving the mechanical properties while being extensively used as conductive electronic materials (Awad et al., 2009).

However, high costs of development, synthesis and commercialization of new polymers is prompting most researchers to look for new materials by reinforcing or blending existing plastic from waste streams, so as to tailormade new materials and properties from the waste streams (Mohanty et al., 2005). The local clay materials and waste polystyrene fall in this category.

Clay materials have been commonly employed to obtain composite materials from polymer matrices, particularly due to the fact that these materials can easily be obtained and applied on a wider scale and level (Modesti et al., 2007; Theng, 2012; Pandey et al., 2013). Also, the structure of clay mineral contents could act as either host matrices or filler in the synthesis of the composites. Likewise, polystyrene is also a low-cost and high performance thermoplastic that finds usage in a variety of applications such as in food and industrial packaging (Zeng, C., \& Lee, 2001). Polystyrene wastes are generated in large quantities, domestically and industrially.

Studies on the development of clay/polystyrene composites and their characterization in terms of electrical, structural, thermal and mechanical properties in non-thermal applications are limited. This study demonstrated that waste polystyrene and local clay can be successfully used to fabricate electrically conductive polymer composites with moderate electrical and physical properties. This capability combined with the ability of solvated polystyrene to fabricate thermoplastic composite without recourse to heat application could open up several new opportunities. 


\section{MATERIALS AND METHODS}

\section{A. Materials}

The clay was obtained locally from Agbede, a water logged area of Tanke, Ilorin which is not far from the University of Ilorin main campus, and crushed to small particle sizes and then dried to remove free water present in it. Thereafter, the clay particles are sieved through a $150 \square \mathrm{m}$ (No. 100) sieve to obtain micro sizes of light brown colour before being admixed with the solvated polystyrene resin. The chemical composition of the clay is presented in Table 1

Table 1: Chemical composition of the raw clay.

\begin{tabular}{cc}
\hline Chemicals & Composition (\%) \\
\hline $\mathrm{SiO}_{2}$ & 56.03 \\
$\mathrm{Al}_{2} \mathrm{O}_{3}$ & 29.72 \\
$\mathrm{Fe}_{2} \mathrm{O}_{3}$ & 1.76 \\
$\mathrm{TiO}_{2}$ & 1.81 \\
$\mathrm{CaO}$ & 0.15 \\
$\mathrm{MgO}$ & 0.14 \\
$\mathrm{Na} 2$ & 0.09 \\
$\mathrm{~K}_{2} \mathrm{O}$ & 1.09 \\
$\mathrm{LOI}\left(\mathrm{H}_{2} \mathrm{O}\right)$ & 9.19 \\
\hline *OI $=$ loss on ignition &
\end{tabular}

The Polystyrene used was basically obtained from solid wastes stream of the University.

\section{B. $\quad$ Preparation of Polystyrene Resin}

The synthetic polystyrene resin was produced from the dissolution of waste polystyrene in petroleum solvent. $59 \mathrm{~g}$ of waste polystyrene was dissolved in $100 \mathrm{ml}$ of the solvent to obtain $145 \mathrm{ml}$ resin weighing $124 \mathrm{~g}$ empirically as reported by Abdulkareem and Adeniyi, 2017. The density of the resultant resin was $855 \mathrm{~kg} / \mathrm{m} 3$ and it re-solidifies at room temperature within 48 hours when left uncovered.

\section{Fabrication of Composites}

The chopped polystyrene bits from waste streams are dissolved in petroleum solvent and the solvated polystyrene was obtained following the procedure reported by Abdulkareem \& Adeniyi, 2017. The graded clay particles are then added to the solvated polystyrene and the mixture thoroughly blended and sonicated for $1.5 \mathrm{hrs}$ based on the schedule proposed in Table 2. The obtained sample in each batch is then cold pressed at room temperature with the aid of single roller mill to get rid of all entrapped air bubbles, and to create composites of rectangular shape and $3 \mathrm{~mm}$ thick amenable for electrical conductivity measurements. Each composite produced is dried at room temperature for 5 days for effective curing. Densities of composites were empirically estimated upon curing and theoretically confirmed. All reported loadings are based upon the weight percent in the final composite
Table 2: Composition of the Plastic composites.

\begin{tabular}{cl}
\hline Composites & Compositions \\
\hline C1 & $100 \%$ matrix $+0 \%$ Clay Particle \\
C2 & $90 \%$ matrix $+10 \%$ Clay Particle \\
C3 & $80 \%$ matrix $+20 \%$ Clay Particle \\
C4 & $70 \%$ matrix $+30 \%$ Clay Particle \\
C5 & $60 \%$ matrix $+40 \%$ Clay Particle \\
\hline
\end{tabular}

\section{Electrical Conductivity Measurement}

The surfaces of the specimens were coated with silver paint to reduce contact resistance. A standard four-point probe using a constant current source (Keithley Instruments Model 6221) was used to obtain bulk volumetric electrical resistivity. The voltage drop across the specimen is recorded, and the resistance of the sample calculated from this measurement. The measured resistances for the composites were then recorded and used to calculate the resistivity of each of the composites. The film resistivity $(\varphi)$ was calculated by using the relation:

$$
\varphi=\frac{R A}{L}
$$

where, $\mathrm{R}$ (ohm) is the measured resistance, $\mathrm{A}(\mathrm{cm} 2)$ is the area of the specimen, $\mathrm{L}(\mathrm{cm})$ is the length of the specimen. The conductivity was obtained as the inverse of the resistivity. The surface morphology of each of the composite sample was observed at magnifications of $40 \mathrm{X}$ and $100 \mathrm{X}$ for each sample using Olympus BX Metallurgical microscope.

\section{E. $\quad$ Measurement of Density}

The experimental densities of the clay, solvated polystyrene and composites were obtained using the laboratory-made density setup. Theoretical densities of the solvated polystyrene/clay composites were calculated by the rule of mixture using the densities of the solvated polystyrene and clay as $0.855 \mathrm{~g} / \mathrm{cm} 3$ and $1.83 \mathrm{~g} / \mathrm{cm} 3$ respectively. For the theoretical density, it was assumed that no voids were present in the samples and no loss of material during the sample preparation. Theoretical densities of the composites were determined using equation 2 ((Osman and Mariatti, 2006).):

$$
\rho_{t d}=\frac{1}{\left(\frac{w_{f}}{\rho_{f}}+\frac{w_{m}}{\rho_{m}}\right)}
$$

where $\mathrm{w}_{\mathrm{f}}$ and $\mathrm{w}_{\mathrm{m}}$ are weight fraction of the filler and matrix respectively while $\rho_{\mathrm{f}}$ and $\rho_{\mathrm{m}}$ are densities of the filler and matrix respectively.

The void content in the composites were estimated by comparing the theoretical density with its actual density using equation 3 (Osman and Mariatti, 2006)

$$
v_{v o i d}=\left(\frac{\rho_{t d}-\rho_{e d}}{\rho_{t d}}\right) * 100
$$

where, $\rho$ td - theoretical density of the composite material $\rho \_$ed- Experimental density of the composite materials. 


\section{RESULTS AND DISCUSSION}

\section{A. Density and Percentage Fraction of Voids}

The theoretical and empirical densities along with the corresponding voids fraction in the solvated polystyrene-clay composites are presented in Table 3. It was observed that the composite density values calculated theoretically from weight fractions using the equation 3 are not equal to the experimentally measured values. This difference is a measure of voids and pores present in the composites (Zeng et al., 2005). It was found that with the increase in clay microparticle content in solvated polystyrene matrix from 0 to $40 \%$, there was a rise in density of the composite by about $11 \%$ although there was a simultaneous decrease in the void fraction or porosity from $5.3 \%$ to $1.5 \%$.

The experimental density was very close to the theoretical density, which implied low voidage presence. This $B$ could be attributed to the fact that the cold processing and pressing of the mix reduced the occurrence of void in eventual plastic composites and in its cured state coupled with the strong adhesive strength of the solvated polystyrene used as the matrix.

Table 3: Densities profile with corresponding void fraction.

\begin{tabular}{|c|c|c|c|c|}
\hline \multirow{2}{*}{$\mathrm{S} / \mathrm{N}$} & \multirow{2}{*}{$\begin{array}{l}\text { Filler } \\
\text { Content } \\
\text { (wt \%) }\end{array}$} & \multicolumn{2}{|c|}{$\begin{array}{l}\text { Density } \\
\text { (Polystyrene/Clay) }\end{array}$} & \multirow{2}{*}{$\begin{array}{l}\text { Void } \\
\text { Fraction } \\
(\%)\end{array}$} \\
\hline & & Theoretical & Experimental & \\
\hline 1 & 0 & 0.8550 & 0.8100 & 5.2632 \\
\hline 2 & 10 & 0.9031 & 0.8800 & 2.5597 \\
\hline 3 & 20 & 0.9570 & 0.9350 & 2.2960 \\
\hline 4 & 30 & 1.0177 & 1.0010 & 1.6369 \\
\hline 5 & 40 & 1.0866 & 1.0700 & 1.5243 \\
\hline
\end{tabular}

The plot of void fraction (\%) against the clay particles content (wt $\%$ ) in Figure 1 shows that there is an inversely proportional relationship between both parameters ( that is, at higher values of the void fraction, the corresponding value for the clay particle content is low in the solvated polystyrene matrix ). It is evident as shown in Table 2 as well as Figure 1 that increased addition of clay particles into the solvated polystyrene matrix leads to the formation of a product composite with lower void fraction and vice versa. This is possible because of the adhesive strength of solvated resin, the mixing efficiency and pressing effect of the roller mill used in the composite fabrication (Linganathan and Samuel, 2014). The density is lighter compared to other thermoplastic composites reported in the literature (Sushant et al., 2017)

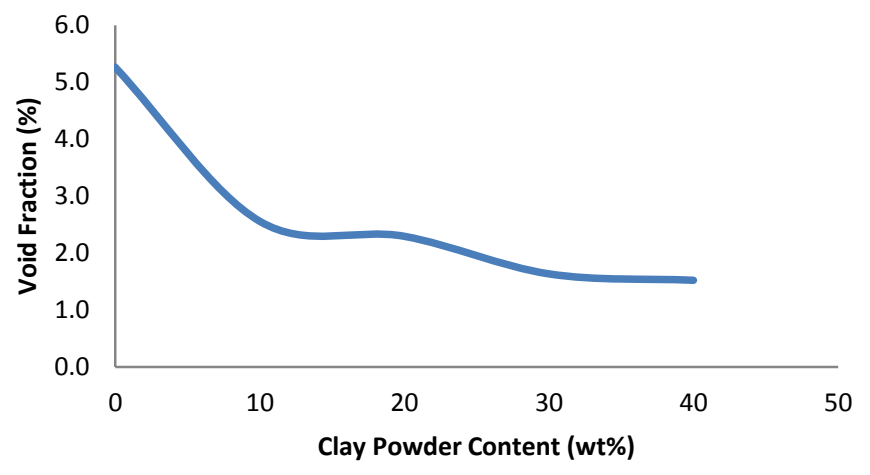

Figure 1: Void fraction (\%) with corresponding clay particle loadings.

\section{B. Electrical Resistance}

Figure 2 shows the effect of filler loading on the electrical resistance of the clay filled polystyrene composites. The results show that the electrical resistance decreased with increase of clay loading. It was observed that beyond $10 \mathrm{wt} \%$ of clay, a significant drop in resistance was observed. In this region, a conductive network is formed through the matrix. This permits the movement of charge carriers of the fillers through the matrix, and so the composite achieves a certain degree of electrical conductivity; in the range of $3.4 \times 10^{-7}$ $(\mathrm{ohm} . \mathrm{cm})^{-1}$ for $10 \%$ clay and $1.9 \times 10^{-7}(\mathrm{ohm} . \mathrm{cm})^{-1}$ for $40 \%$ clay which is electrostatic dissipative in nature (Linganathan and Samuel, 2014) as presented in Table 4. As the clay content increases, the number of conductive paths increases, the average distance between the clay particles becomes smaller and consequently the resistance of the composite decreases.

. The principle and pattern of the composite is semiconductor in nature in line with the works of Linganathan and Samuel, 2014

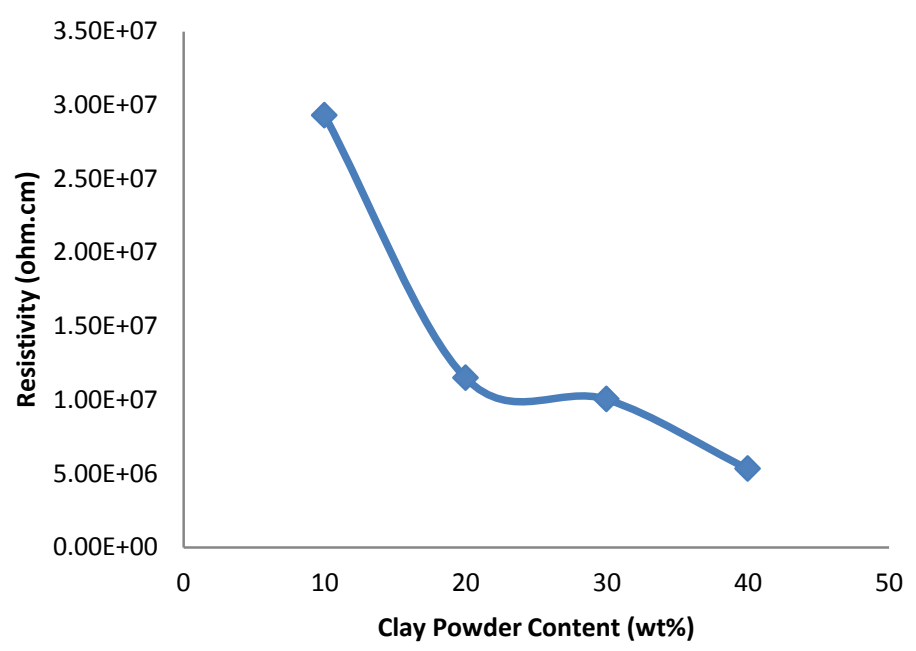

Figure 2: Resistivity value with corresponding clay particle loadings. 
Table 4: Effects of Filler Content on the Electrical Conductivity.

\begin{tabular}{|c|c|}
\hline Clay Content (wt \%) & Conductivity $(\mathrm{Ohm} . \mathrm{cm})^{-1}$ \\
\hline 10 & $3.41356 \mathrm{E}-08$ \\
\hline 20 & 8.71052E-08 \\
\hline 30 & $9.96035 \mathrm{E}-08$ \\
\hline 40 & $1.87973 \mathrm{E}-07$ \\
\hline
\end{tabular}

\section{B. Microscopic Analysis}

Micrographs of composites at 10, 20,30 and 40\% filler content, at 40 and $100 \mathrm{X}$ magnifications are presented in Table 5. It can be seen that clay filler are dispersed in the polystyrene with no significant separation by the insulating matrix. It can be observed that the semi-conductive path is established which is traceable to the composition of the clay obtained from in site in Ilorin. The growing intensity of particle networks and physical contact among clay particles led to the moderately decreasing electrical resistance behaviour in clay-polystyrene composites developed (Alam, 2008).

Table 5: Micrographs of Conductive Composites at 40 and $100 \mathrm{X}$ for Different Filler Content.

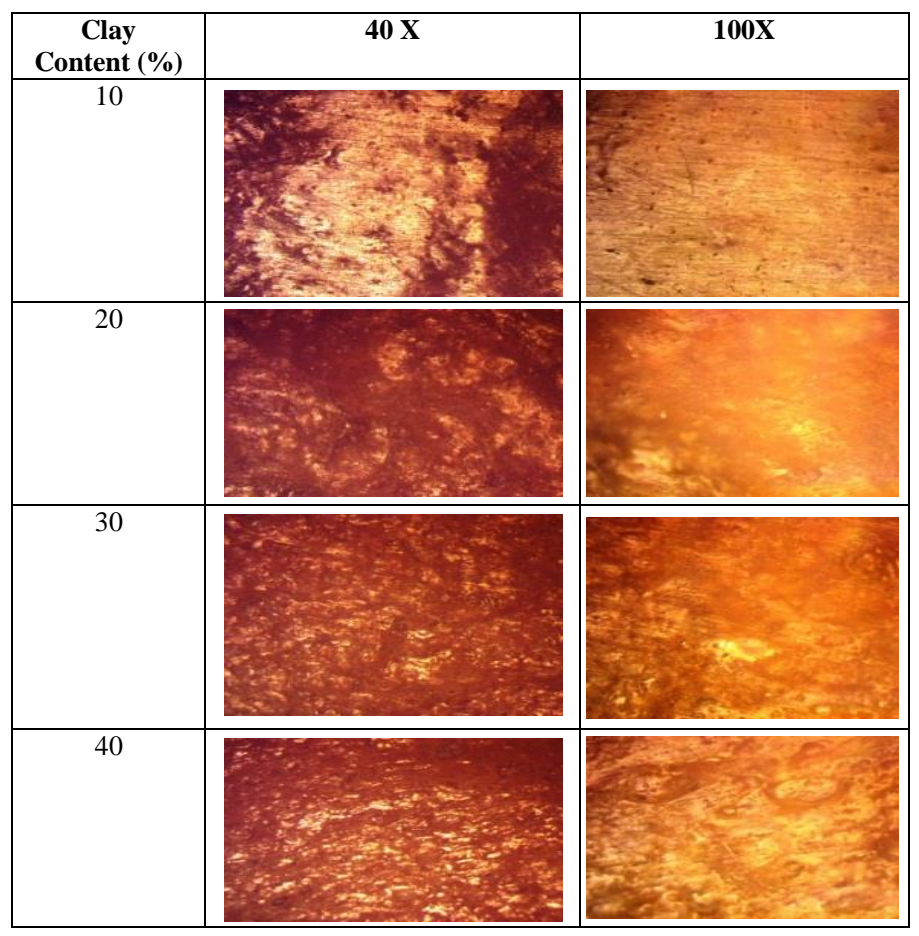

\section{CONCLUSION}

This research work, aimed at preparing plastic composite from recycled polystyrene and local clay and determining the electrical properties, was presented. The aim of the study has been successfully achieved. The following conclusions can be drawn from the work:

(i) The experimental investigation revealed that the electrical conductivities increased as clay content increased in the plastic composites produced and the measured densities were very close to that of theoretical.

(ii) The good dispersion of filler material in the plastic matrix is confirmed by the micrographic photographs of the composites.

\section{REFERENCES}

Abdulkareem S. A. and Adeniyi A. G., (2017) Production of Particleboards Using Polystyrene and Bamboo Wastes Nigerian Journal of Technology (NIJOTECH), $36 \quad$ (3): 6571.

Alam, S. M. M. (2008). PI-clay nanocomposites: Synthesis and characterization. Paper presented at the Electrical and Computer Engineering, 2008. ICECE 2008. International Conference, Bangladesh.

Awad, W. H.; G. Beyer; D. Benderly; W. L. Ijdo; P. Songtipya; M. Del Mar Jimenez- Gasco; C. A. Wilkie (2009). Material properties of nanoclay PVC composites. Polymer, 50(8), 1857-1867

Linganathan P, Samuel J M (2014), Synthesis, Characterization and Electrical Conductivity of Poly (2Chloroaniline)/Mmt And Poly (2-Chloroaniline)/Na-Bentonite Nano Composites in The Presence of Surfactants, International Journal of Scientific \& Technology Research, 3 (2): 56-61.

Modesti, M.; S., Besco, A.; Lorenzetti, V.; Causin, C. Marega; J. Gilman; M. Zammarano, (2007). ABS/clay nanocomposites obtained by a solution technique: Influence of clay organic modifiers. Polymer degradation and Stability, 92(12): 2206-2213.

Mohanty; A. K., M.; Misra \& L. T. Drzal (2005). Natural fibers, biopolymers, and biocomposites: CRC Press.

Osman A.F. and Mariatti M; (2006), Properties of Aluminum Filled Polypropylene Composites; Polymers \& Polymer Composites, 14 (6): 23 - 29.

Pandey, S.; M., Zaidib, \& S., Gururani (2013). Recent developments in clay-polymer nano composites. Scientific Journal of Review, 2(11): 296-328

Sushant D. S.; C. R.; Umesh D.G.; Roshan M. K Jaydeep,(2017) Preparation of Polyphenylenesulfide (PPS)/Clay Nano Composite and Its Characterisation, International Conference on Ideas, Impact and Innovation in Mechanical Engineering (ICIIIME 2017), 5 (6): 340 - 346

Tanniru, M.; Q. Yuan; \& R. Misra(2006). On significant retention of impact strength in clay-reinforced highdensity polyethylene (HDPE) nanocomposites. Polymer, 47(6): 2133-2146

Theng, B. K. G. (2012). Formation and properties of claypolymer complexes, vol 4, $2^{\text {nd }}$ ed. Elsevier, UK.

Wang, Y. (2006). Conductive thermoplastic composite blends for flow field plates for use in polymer electrolyte membrane fuel cells (PEMFC). University of Waterloo, available online at http://hdl.handle.net/10012/2893

Zeng, C., \& Lee, L. J. (2001). Poly (methyl methacrylate) and polystyrene/clay nanocomposites prepared by in-situ polymerization. Macromolecules, 34(12): 4098-4103.

Zeng, Q.; Yu, A.; Lu, G.; \& D. Paul, (2005). Clay-based polymer nanocomposites: research and commercial development. Journal of nanoscience and nanotechnology, 5(10): 1574-1592. 